\title{
BIBECHANA
}

A Multidisciplinary Journal of Science, Technology and Mathematics ISSN 2091-0762 (Print), 2382-5340 (0nline)

Journal homepage: http://nepjol.info/index.php/BIBECHANA

Publisher: Research Council of Science and Technology, Biratnagar, Nepal

\section{Solvation free energy of light alkanes in polar and amphiphilic environments}

\author{
Sunil Pokharel, Shyam Prakash Khanal, N. P. Adhikari* \\ Central Department of Physics, Tribhuvan University, Kirtipur, Nepal \\ *Email: npadhikari@gmail.com \\ Article history: Received 3 May, 2018; Accepted 22 September, 2018 \\ DOI: http://dx.doi.org/10.3126/bibechana.v16i0.21136
}

This work is licensed under the Creative Commons CC BY-NC License. https://creativecommons.org/licenses/by$\underline{\mathrm{nc} / 4.0 /}$

\section{Abstract}

Computer simulations of molecular models are powerful technique that have improved the understanding of many biochemical phenomena. The method is frequently applied to study the motions of biological macromolecules such as protein and nucleic acids, which can be useful for interpreting the results of certain biophysical experiments. In this work, we have estimated the solvation free energy for light alkane (methane, ethane, propane and n-butane) dissolved in water and methanol respectively over a broad range of temperatures, from $275 \mathrm{~K}$ to $375 \mathrm{~K}$, using molecular dynamics simulations. The alkane (methane, ethane, propane and n-butane), and methanol molecules are described by the OPLS-AA (Optimized Potentials for Liquid Simulations-All Atom) potential, while water is modeled by TIP3P (Transferable Intermolecular Potential with 3-Points) model. We have used the free energy perturbation method (Bennett Acceptance Ratio (BAR) method) for the calculation of free energy of solvation. The estimated values of solvation free energy of alkane in the corresponding solvents agree well with the available experimental data.

Keywords: Alkane; Free Energy; Molecular dynamics; BAR.

\section{Introduction}

Solubility, lack of solubility and other solvation properties of atoms, molecules and ions in aqueous solutions play a crucial role in biological processes and industrial applications. The free energy of solvation (specifically, hydration) is one of the most important properties in the study of solvent effects which determines solubilities, partition coefficients, association, dissociation, and binding constants, phase equilibria, and for transition states, reaction rates in many bio-chemical and physical processes [1]. For instance, protein folding occurs spontaneously because of a favorable change in the interactions between the protein and the surrounding water molecules. The folded proteins, caused by combined 
effects of solvent and hydrogen bonding, are stable by $5-10 \mathrm{kcal} / \mathrm{mol}$. The solvation is driven by minimizing the number of side-chains, exposed to water and hydrophobic in nature, covered by the folded protein at its centre [2]. The host-guest complexes, whose binding constant depends on solvent polarity, caused by hydrophobic pores present in host molecules also act as driving force for solvation [3]. Furthermore, the interactions can be used in biological system to deliver the hydophobic drugs. Hydration has effects on electronic and vibrational properties of biomolecule $[4,5]$.

Computer simulation and modeling is performed in order to comprehend the properties of assemblies of molecules in terms of their structure and the microscopic interactions between them. In a classical framework, the main computational methods are molecular dynamics (MD) and Monte Carlo (MC) simulations. Molecular Dynamics (MD) simulation is a powerful approach for predicting and knowing the structure, function, dynamics, and interactions of atoms and molecules starting from a simple to complex systems in biophysical phenomenon of materials science study. These techniques are complement to conventional experiments, enabling us to learn something new, something that cannot be found out in other ways [6-11].

Alkanes are saturated hydrocarbons that consist only of the elements carbon $(\mathrm{C})$ and hydrogen $(\mathrm{H})$, where each of these atoms are linked together exclusively by single bonds. Alkanes belong to a homologous series of organic compounds in which the members differ by a constant molecular mass of 14 that is $\mathrm{CH}_{2}$ [12]. First four members (lighter alkanes) of alkane series are methane, ethane, propane, and butane with molecular formula $\mathrm{CH}_{4}, \mathrm{C}_{2} \mathrm{H}_{6}, \mathrm{C}_{3} \mathrm{H}_{8}$, and $\mathrm{C}_{4} \mathrm{H}_{10}$ respectively. The most important sources of alkanes are natural gas and crude oil. Alkanes are non-polar solvents as only $\mathrm{C}$ and $\mathrm{H}$ atoms are present. Methane, ethane, propane and n-butane are hydrophobic molecules, and as such its solubility in water is rather low, and they tend to aggregate when solvated in water, but freely soluble in non-polar solvent like ether and benzene. This behavior is more clearly exhibited by longer n-alkane chains, which may be considered as polymers of methane. The complicated organic compounds that once made up living plants or animals have transformed into a mixture of alkanes [12-16]. Furthermore, the first four members of alkanes are also neutral analogs of amino acid side chain. Amino acid side chain analogs represent a natural test case for biomolecular interaction $[17,18]$. Transport properties such as diffusion, viscosity and thermodynamic properties like free energy of hydration/solvation of hydrocarbons (alkanes) in aqueous environment is a basic consideration in many processes like processing of natural gases and petroleum, understanding the tertiary structure of proteins, as well as the important role it plays as a driving force in a number of processes occurring within living cells [1921]. The free energy of hydration of light alkanes (a polar molecule) for a few temperatures and pressures have been repeatedly measured by computer simulations but the experimental values are rare. On the other hand, there is no literature data for the free energy of solvation of light alkanes in methanol (an amphiphilic molecule). So, we are motivated to calculate the free energy of hydration/solvation of light alkanes in water and ethanol molecules. Our findings from the numerical simulation can also be used as a crude reference for any further studies of hydrophobicity and solubility of organic and inorganic substances in different solvent environments.

The outline of the paper is as follows: In Sec. II, we discuss the theoretical background of the free energy of solvation and method of calculation. Computational details of our work are stated in Sec. III. Results of the work are presented in Secs. IV. Our conclusions are collected in Sec. V. 


\section{Theoretical Background}

A thermodynamic quantity equivalent to the capacity of a system to do work, the difference between internal energy of the system and the amount of energy that cannot be used to perform work, is known as free energy of the system. Mathematically, the Helmholtz free energy $\mathrm{A}(\mathrm{N}, \mathrm{V}, \mathrm{T})$ and the Gibbs free energy $\mathrm{G}(\mathrm{N}, \mathrm{P}, \mathrm{T})$ are defined as:

$$
\begin{aligned}
& \mathrm{A}=\mathrm{U}-\mathrm{TS} \\
& \mathrm{G}=\mathrm{A}+\mathrm{PV}=\mathrm{U}-\mathrm{TS}+\mathrm{PV}=\mu \mathrm{N}
\end{aligned}
$$

where, $\mathrm{U}, \mathrm{S}$ and $\mu$ are internal energy, entropy and chemical potential of the system respectively. The Helmholtz free energy $\mathrm{A}(\mathrm{N}, \mathrm{V}, \mathrm{T})$ describes a closed, isochoric, isothermal assembly, so it is a function of temperature $(\mathrm{T})$, volume $(\mathrm{V})$, and number of molecules $(\mathrm{N})$. The Gibbs free energy $\mathrm{G}(\mathrm{N}, \mathrm{P}, \mathrm{T})$ describes a closed isobaric, isothermal assembly, so it is a function of temperature ( $\mathrm{T})$, pressure $(\mathrm{P})$, and number of molecules $(\mathrm{N})[22,23]$. The chemical potential is given by

$$
\mu=\left(\frac{\partial \mathrm{A}}{\partial \mathrm{N}}\right)_{\mathrm{T}, \mathrm{V}}=\left(\frac{\partial \mathrm{G}}{\partial \mathrm{N}}\right)_{\mathrm{T}, \mathrm{P}}
$$

Two ensembles are particularly useful for the calculations of free energy: the canonical (NVT) ensemble and the isobaric-isothermal (NPT) ensemble. The Helmholtz free energy and Gibbs free energy are determined by the corresponding partition functions $Q$ defined by [22, 23]:

$$
\begin{gathered}
\mathrm{A}(\mathrm{N}, \mathrm{V}, \mathrm{T})=\mathrm{k}_{\mathrm{B}} \mathrm{T} \ln \mathrm{Q}_{\mathrm{N}}(\mathrm{V}, \mathrm{T})=\frac{1}{\mathrm{~N} ! \mathrm{h}^{3 \mathrm{~N}}} \times \int \mathrm{e}^{-\beta \mathrm{H}_{0}(\mathrm{p}, \mathrm{q})} \mathrm{dpdq} \\
\text { and } \quad \mathrm{G}(\mathrm{N}, \mathrm{P}, \mathrm{T})=\mathrm{k}_{\mathrm{B}} \mathrm{T} \ln \mathrm{Q}_{\mathrm{N}}(\mathrm{P}, \mathrm{T})=\frac{1}{\mathrm{~N} ! \mathrm{h}^{3 \mathrm{~N}}} \times \int \mathrm{e}^{-\beta \mathrm{PV}} \mathrm{Q}_{\mathrm{N}}(\mathrm{V}, \mathrm{T}) \mathrm{dV}
\end{gathered}
$$

where $\beta=1 / \mathrm{k}_{\mathrm{B}} \mathrm{T}, \mathrm{H}_{0}$ is the unperturbed Hamiltonian of the system and $\mathrm{V}$ is the volume. In simulation, the direct measurement of the free energy is not possible but difference in free energy can be calculated. For any other system differing in the Hamiltonian by a perturbation of the potential energy(U), $\mathrm{H}_{\mathrm{p}}=\mathrm{H}_{0}+\mathrm{U}$, the dfference in Helmholtz free energy is,

$$
\Delta \mathrm{A}=\mathrm{A}_{\mathrm{p}}-\mathrm{A}_{0}=-\mathrm{k}_{\mathrm{B}} \mathrm{T} \ln \left(\frac{\mathrm{Q}_{\mathrm{P}}}{\mathrm{Q}_{0}}\right)
$$

Free energy calculations have a number of practical applications, of which some of the more common ones include free energies of solvation/hydration and free energy of binding for a small molecule to some larger receptor biomolecule (usually a protein). Equilibrium free energy methodologies share the common strategy of generating equilibrium ensembles of configurations at multiple values of the scaling parameter $\lambda$. The commonly used methods are thermodynamic integration [24], adaptive integration [25], multistage free energy perturbation [26], and multistage equilibrium Bennett analysis [27]. In GROMACS, different approaches, including "slow-growth" can be used to calculate the free energy differences. In the "slow-growth" method, the Hamiltonian of system, that changes slowly to remain in equilibrium from one system A to other system $B$, is modified by making the Hamiltonian as function of coupling parameter $\lambda$ as $\mathrm{H}(\mathrm{p}, \mathrm{q} ; \lambda)$ such that $\mathrm{H}(\mathrm{p}, \mathrm{q} ; 0)=\mathrm{H}^{\mathrm{A}}(\mathrm{p}, \mathrm{q})$ and $\mathrm{H}(\mathrm{p}, \mathrm{q} ; 1)=$ $\mathrm{H}^{\mathrm{B}}(\mathrm{p}, \mathrm{q})$. The Helmholtz free energy $A(\mathrm{~N}, \mathrm{~V}, \mathrm{~T})$ in terms of partition function $\mathrm{Q}$ is defined as $[22,23$, 36]:

$$
A(\lambda)=-k_{B} T \ln Q_{T}(V, T)=\frac{1}{N ! h^{3 N}} \times \int e^{-\beta H_{0}(p, q ; \lambda)} d p d q
$$

where $\beta=1 / k_{B} T, H(p, q ; \lambda)$ is the Hamiltonian of the system.

In order to calculate free energy difference, we define potential energy function which linearly depends on coupling parameters $\lambda$ i.e. $U(\lambda)$ such that, for $\lambda=0, U_{A}(\lambda=0)$ represents the potential energy of system $A$ and $U_{B}(\lambda=1)$ represents the potential energy of system $B$, then

$$
\mathrm{U}(\lambda)=(1-\lambda) \mathrm{U}_{\mathrm{B}}+\lambda \mathrm{U}_{\mathrm{A}}=\mathrm{U}_{\mathrm{A}}+\lambda\left(\mathrm{U}_{\mathrm{B}}-\mathrm{U}_{\mathrm{A}}\right)
$$


Also, the derivative of Helmoltz free energy Eq. (7) with respect to coupling parameter $\lambda$ and using Eq. (8), we get the relation as:

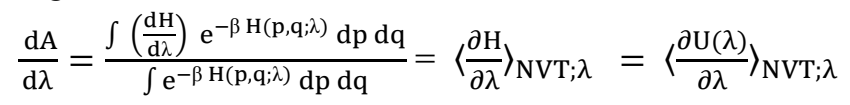

The $\langle\ldots\rangle$ brackets represent the ensemble average. After integrating the Eq.(9) from $\lambda=0$ to $\lambda=1$ using thermodynamic integration (TI) method, we can evaluate the free energy difference between the system $\mathrm{A}$ and $\mathrm{B}$ as

$$
\Delta \mathrm{A}=\mathrm{A}^{\mathrm{B}}(\mathrm{V}, \mathrm{T})-\mathrm{A}^{\mathrm{A}}(\mathrm{V}, \mathrm{T})=\int_{0}^{1}\left\langle\frac{\partial \mathrm{H}}{\partial \lambda}\right\rangle_{\mathrm{NVT} ; \lambda} \mathrm{d} \lambda=\int_{0}^{1}\left\langle\frac{\partial \mathrm{U}(\lambda)}{\partial \lambda}\right\rangle_{\mathrm{NVT} ; \lambda} \mathrm{d} \lambda
$$

According to the Bennett Acceptance Ratio (BAR) [27] method, the ratio of partition function $\mathrm{Q}_{0}$ for $\lambda=0$ and $\mathrm{Q} 1$ for $\lambda=1$ is given by:

$$
\frac{Q_{0}}{Q_{1}}=\frac{Q_{0} \int w\left(r^{N}\right) e^{-\beta\left(U_{0}+U_{1}\right)} d r^{N}}{Q_{1} \int w\left(r^{N}\right) e^{-\beta\left(U_{0}+U_{1}\right)} d r^{N}}=\frac{\left\langle w e^{\left.-\beta U_{0}\right\rangle_{1}}\right.}{\left\langle w e^{\left.-\beta U_{1}\right\rangle_{0}}\right.}
$$

where ' $w$ ' is an arbitrary weight function. In terms of ' $w$ ', the Helmoltz free energy difference is given by

$$
\beta \Delta \mathrm{A}=\ln \left\langle\mathrm{w} \mathrm{e}^{-\beta \mathrm{U}_{0}}\right\rangle_{1}-\ln \left\langle\mathrm{w} \mathrm{e}^{-\beta \mathrm{U}_{1}}\right\rangle_{0}
$$

It is also possible to use Bennetts method to combine the information normally used for forward and reverse free energy perturbations. In this approach, we compute the free energy difference between successive $\lambda$ values $\delta \mathrm{A}$ according to the relation

$$
\left\langle\left[1+\mathrm{e}^{\beta\left(\mathrm{U}_{\lambda_{\mathrm{i}+1}}\left(\mathrm{x}_{\mathrm{i}}\right)-\mathrm{U}_{\lambda_{\mathrm{i}}}\left(\mathrm{x}_{\mathrm{i}}\right)-\delta \mathrm{A}_{\mathrm{i}}\right)}\right]^{-1}\right\rangle_{\lambda_{\mathrm{i}}}=\left\langle\left[1+\mathrm{e}^{\beta\left(\mathrm{U}_{\lambda_{\mathrm{i}+1}}\left(\mathrm{x}_{\mathrm{i}+1}\right)-\mathrm{U}_{\lambda_{\mathrm{i}}}\left(\mathrm{x}_{\mathrm{i}+1}\right)+\delta \mathrm{A}_{\mathrm{i}}\right)}\right]^{-1}\right\rangle_{\lambda_{\mathrm{i}}+1}
$$

Then the sum of these $\delta \mathrm{A} i$ is the total Helmholtz free energy difference [27],

$$
\Delta \mathrm{A}=\sum_{\mathrm{i}=0}^{\mathrm{n}-1} \delta \mathrm{A}_{\mathrm{i}}
$$

\section{Computational Model}

\section{A. Molecular Models}

The TIP3P (Transferable Intermolecular Potential with 3-Points) model [28] is used in all the simulation for water as a solvent. The OPLSS-AA (Optimized Potentials for Liquid Simulations-All Atom) potential model [29] is used for alkanes (methane, ethane, propane, n-butane) and methanol. The all atom model of the studied alkane system is shown in figure (1). The system under study consists of 1 alkane (methane, ethane, propane, n-butane) molecule and 596 water, and 1 alkane (methane, ethane, propane, n-butane) molecule and 354 methanol, a separate system separately. In classical force fields like OPLS-AA, the potential functions are derived empirically to describe the atomic interactions. The atoms are treated as spherically symmetric particles and are considered to be connected through covalent bonds to form molecules. Each and every atom experiences a force resulting from its pairwise additive interac- tions with the rest of the system. The total potential energy $U$ tot includes contributions from both bonded and non-bonded interactions [36]. The bonded interactions are bond stretching (2body), bond angle (3- body) and dihedral angle (4-body) interactions. A special type of dihedral interaction (called improper dihedrals) is used to force atoms to remain in a plane or to prevent transition to a configuration of opposite chirality (a mirror image). The non-bonded interactions are represented by the Lennard-Jones potential and Coulomb potential. Therefore, the total potential energy function of a system can be written as [36]:

$$
\mathrm{U}_{\text {tot }}=\mathrm{U}_{\text {bonded }}+\mathrm{U}_{\text {non-bonded }}=\mathrm{U}_{\text {bond }}+\mathrm{U}_{\text {angle }}+\mathrm{U}_{\text {dihedral }}+\mathrm{U}_{\mathrm{LJ}}+\mathrm{U}_{\text {Coul }}
$$




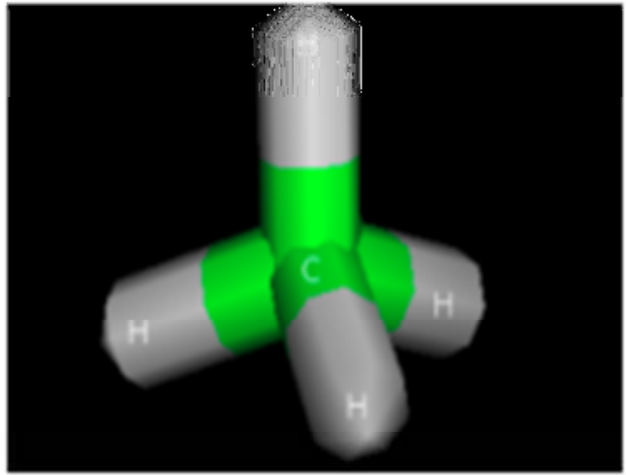

(a)

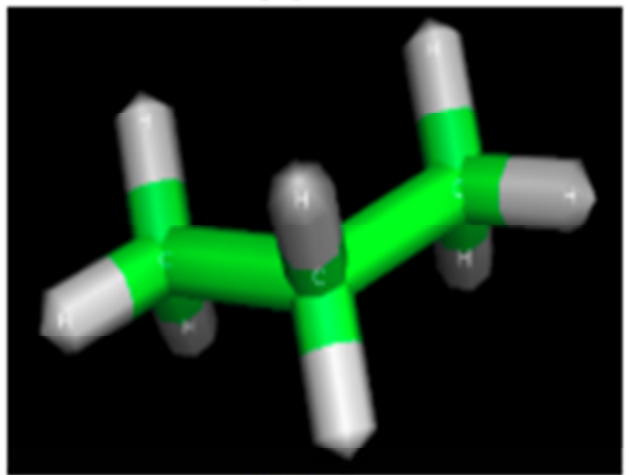

(c)

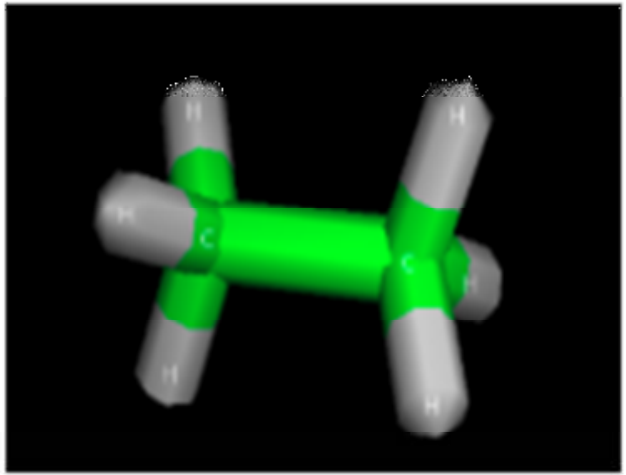

(b)

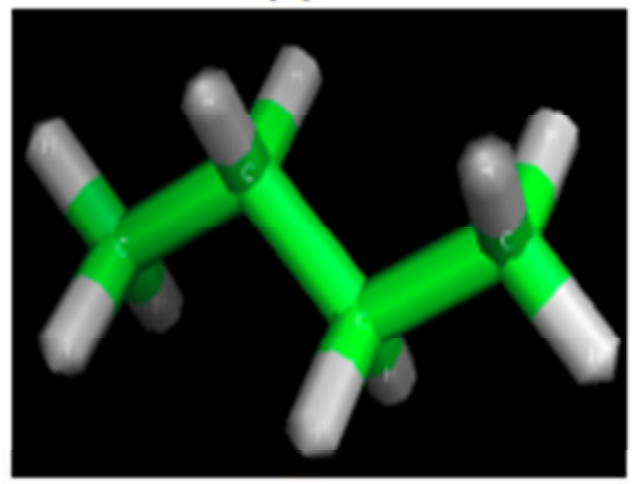

(d)

Fig. 1: Pymol snapshots of light alkanes (a) Methane, (b) Ethane, (c) Propane and (d) n-Butane model used in this work.

The bond stretching between two covalently bonded atoms $i$ and $j$ is represented by harmonic potential [36]

$$
\mathrm{U}_{\text {bond }}\left(\mathrm{r}_{\mathrm{ij}}\right)=\frac{1}{2} \mathrm{k}_{\mathrm{ij}}^{\mathrm{b}}\left(\mathrm{r}_{\mathrm{ij}}-\mathrm{b}_{\mathrm{ij}}\right)^{2}
$$

where $\mathrm{k}_{\mathrm{ij}}^{\mathrm{b}}$ is the force constant and $b_{\mathrm{ij}}$ is the equilibrium bond length between two atoms $\mathrm{i}$ and $\mathrm{j}$. The bond angle vibration between a triplet of atoms $\mathrm{i}-\mathrm{j}-\mathrm{k}$ is also represented by a harmonic potential on the angle $\theta_{\mathrm{ijk}}$ [36]

$$
\mathrm{U}_{\text {angle }}\left(\theta_{\mathrm{ijk}}\right)=\frac{1}{2} \mathrm{k}_{\mathrm{ijk}}^{\Theta}\left(\Theta_{\mathrm{ijk}}-\Theta_{\mathrm{ijk}}^{0}\right)^{2}
$$

where $\mathrm{k}_{\mathrm{ijk}}^{\Theta}$ is the force constant and $\Theta_{\mathrm{ijk}}^{0}$ is the equilibrium bond angle.

The proper dihedral angle is defined as the angle between the ijk and jkl planes. In this study, we have used thefollowing dihedral potential (Ryckaert-Bellmans potential) [36] for alkanes:

$$
\mathrm{U}_{\mathrm{RB}}=\mathrm{c}_{0}+\mathrm{c}_{1}(1+\cos \varphi)+\mathrm{c}_{2}(1-\cos 2 \varphi)+\mathrm{c}_{3}(1+\cos 3 \varphi)
$$

where $\varphi$ is the dihedral angle and $c_{0}, c_{1}, c_{2}, c_{3}$ are constants. The bonded parameters for water and alkanes are given in the table (I). 
Table I: Force-field (bonded) parameters for TIP3P wa- ter and OPLS-AA alkanes and methanol. The units of equilibrium bond length (b) and equilibrium bond angle $\left(\Theta_{0}\right)$ are nanometer $(\mathrm{nm})$ and degrees (o) respectively. Similarly, the units of $\mathrm{k}^{\mathrm{b}}, \mathrm{k}^{\Theta}$ and $\mathrm{c}_{\mathrm{i}}\left(\mathrm{c}_{0}, \mathrm{c}_{1}, \mathrm{c}_{2}, \mathrm{c}_{3}\right)$ are $\mathrm{kJmol}-1 \mathrm{~nm}-2, \mathrm{kJmol}^{-1} \mathrm{rad}^{-2}$ and $\mathrm{kJmol}^{-1}$ respectively.

\begin{tabular}{|c|c|c|c|c|}
\hline $\begin{array}{l}\text { TIP3P } \\
\text { Water }\end{array}$ & $\begin{array}{c}\mathrm{k}_{\mathrm{OH}}^{\mathrm{b}} \\
\mathrm{k}_{\mathrm{HOH}}^{\ominus}\end{array}$ & $\begin{array}{c}502415.0 \\
628.02\end{array}$ & $\begin{array}{c}\mathrm{b}_{\mathrm{OH}} \\
\Theta_{\mathrm{HOH}}^{0}\end{array}$ & $\begin{array}{l}0.09572 \\
104.52\end{array}$ \\
\hline & $\mathrm{k}_{\mathrm{CH}}^{\mathrm{b}}$ & 284512.0 & $\mathrm{~b}_{\mathrm{CH}}$ & 0.1090 \\
\hline OPLS-AA & $\mathrm{k}_{C \mathrm{C}}^{\mathrm{b}}$ & 224262.4 & $\mathrm{~b}_{\mathrm{CC}}$ & 0.1529 \\
\hline \multirow[t]{3}{*}{ Alkanes } & $\mathrm{k}_{\mathrm{HCH}}^{\Theta}$ & 276.144 & $\Theta_{\mathrm{HCH}}^{0}$ & 109.47 \\
\hline & $\mathrm{k}_{\mathrm{H} C \mathrm{\theta}}^{\Theta}$ & 313.800 & $\Theta_{\mathrm{HCC}}^{0}$ & 109.47 \\
\hline & $\mathrm{k}_{\mathrm{CCC}}^{\Theta}$ & 488.273 & $\theta_{\mathrm{CCC}}^{0}$ & 109.47 \\
\hline \multicolumn{5}{|c|}{ Dihedral Potential (Alkanes) } \\
\hline \multirow[t]{2}{*}{$\mathrm{H}-\mathrm{C}-\mathrm{C}-\mathrm{H}$} & $\mathrm{C}_{0}$ & 0.62760 & $\mathrm{C}_{0}$ & 1.88280 \\
\hline & $\mathrm{C}_{2}$ & 0.00000 & $\mathrm{C}_{2}$ & -2.51040 \\
\hline \multirow[t]{3}{*}{$\mathrm{H}-\mathrm{C}-\mathrm{C}-\mathrm{C}$} & $\mathrm{C}_{0}$ & 0.62760 & $\mathrm{C}_{0}$ & 1.88280 \\
\hline & $\mathrm{C}_{2}$ & 0.00000 & $\mathrm{C}_{2}$ & -2.51040 \\
\hline & $\mathrm{C}_{0}$ & 2.92880 & $\mathrm{C}_{0}$ & -1.46440 \\
\hline $\mathrm{C}-\mathrm{C}-\mathrm{C}-\mathrm{C}$ & $\mathrm{C}_{2}$ & 0.20920 & $\mathrm{C}_{2}$ & -1.67360 \\
\hline \multicolumn{5}{|c|}{ Dihedral Potential (Methanol) } \\
\hline \multirow[t]{2}{*}{$\mathrm{H}-\mathrm{C}-\mathrm{OH}-\mathrm{HO}$} & $\mathrm{C}_{0}$ & 0.94140 & $\mathrm{C}_{0}$ & 2.82420 \\
\hline & $\mathrm{C}_{2}$ & 0.00000 & $\mathrm{C}_{2}$ & -3.76560 \\
\hline \multirow[t]{2}{*}{$\mathrm{H}-\mathrm{C}-\mathrm{C}-\mathrm{C}$} & $\mathrm{C}_{0}$ & 0.62760 & $\mathrm{C}_{0}$ & 1.88280 \\
\hline & $\mathrm{C}_{2}$ & 0.00000 & $\mathrm{C}_{2}$ & -2.51040 \\
\hline \multirow[t]{2}{*}{ C-C-C-C } & $\mathrm{C}_{0}$ & 2.92880 & $\mathrm{C}_{0}$ & -1.46440 \\
\hline & $\mathrm{C}_{2}$ & 0.20920 & $\mathrm{C}_{2}$ & -1.67360 \\
\hline
\end{tabular}

The non-bonded inter-atomic interaction is the sum of Lennard-Jones interaction (ULJ) and Coulomb interaction (UCoul), that can be written as:

$$
\mathrm{U}_{\alpha \beta}\left(\mathrm{r}_{\mathrm{ij}}\right)=4 \epsilon_{\alpha \beta}\left[\left(\frac{\sigma_{\alpha \beta}}{\mathrm{r}_{\mathrm{ij}}}\right)^{12}-\left(\frac{\sigma_{\alpha \beta}}{\mathrm{r}_{\mathrm{ij}}}\right)^{6}\right]+\frac{\mathrm{q}_{\mathrm{i} \alpha} \mathrm{q}_{\mathrm{j} \beta}}{4 \pi \epsilon_{0} \mathrm{r}_{\mathrm{ij}}}
$$

where rij is the Cartesian distance between the two atoms $\mathrm{i}$ and $\mathrm{j} ; \alpha$ and $\beta$ indicate the type of the atoms. The non-bonded parameters for alkanes and water is given in the table (II).

Table II: Force-field (non-bonded) parameters for TIP3P water and OPLS-AA alkanes and methanol.

\begin{tabular}{|c|c|c|c|c|}
\hline & Atoms & $\sigma(\mathrm{nm})$ & $\epsilon\left(\mathrm{kJ} / \mathrm{mol}^{\prime}\right.$ & Charge (q) \\
\hline TIP3P & OW & 0.315061 & 0.636386 & $-0.834 \mathrm{e}$ \\
\hline Water & HW & 0.000000 & 0.000000 & $+0.417 \mathrm{e}$ \\
\hline \multirow{4}{*}{$\begin{array}{l}\text { OPLS-AA } \\
\text { Alkanes }\end{array}$} & $\mathrm{C}\left(\mathrm{CH}_{4}\right)$ & 0.35000 & 0.276144 & $0.000 \mathrm{e}$ \\
\hline & $\mathrm{C}\left(\mathrm{CH}_{3}\right)$ & 0.35000 & 0.276144 & $0.000 \mathrm{e}$ \\
\hline & $\mathrm{C}\left(\mathrm{CH}_{2}\right)$ & 0.35000 & 0.276144 & $0.000 \mathrm{e}$ \\
\hline & $\mathrm{H}$ & 0.25000 & 0.125520 & $0.000 \mathrm{e}$ \\
\hline \multirow{4}{*}{$\begin{array}{l}\text { OPLS-AA } \\
\text { Methanol }\end{array}$} & $\mathrm{C}\left(\mathrm{CH}_{3}\right)$ & 0.35000 & 0.276144 & $+0.145 \mathrm{e}$ \\
\hline & $\mathrm{C}\left(\mathrm{CH}_{2}\right)$ & 0.25000 & 0.125520 & $+0.040 \mathrm{e}$ \\
\hline & $\mathrm{OH}$ & 0.312000 & 0.711280 & $-0.683 \mathrm{e}$ \\
\hline & $\mathrm{HO}$ & 0.00000 & 0.000000 & $+0.418 \mathrm{e}$ \\
\hline
\end{tabular}


Here OW and HW represent the oxygen and hydrogen atoms of the water molecules respectively and $\mathrm{C}\left(\mathrm{CH}_{4}\right), \mathrm{C}\left(\mathrm{CH}_{3}\right)$ and $\mathrm{C}\left(\mathrm{CH}_{2}\right)$ are the methane, methyl and methylene carbon atoms of the alkane molecules respectively. Similarly, $\mathrm{OH}$ and $\mathrm{HO}$ are oxygen and hydrogen atoms of hydroxyl group of methanol respectively. The parameters for the non-bonded Lennard-Jones interaction between two different atoms for OPLS-AA force field are written as [36]:

$$
\begin{aligned}
& \sigma_{\alpha \beta}=\left(\sigma_{\alpha \alpha} \times \sigma_{\beta \beta}\right)^{\frac{1}{2}} \\
& \epsilon_{\alpha \beta}=\left(\epsilon_{\alpha \alpha} \times \epsilon_{\beta \beta}\right)^{\frac{1}{2}}
\end{aligned}
$$

\section{B. Simulation Procedure}

Molecular dynamics simulation was carried out in a cubic box with periodic boundary conditions [7] using GROMACS 5.1.1 [37, 38, 47 ]. The distance to the edge of the box from the solute (alkane) is an important parameter for defining the size of the box. Since we are using periodic boundary conditions, we must satisfy the minimum image convention. That is alkane (solute) should never see its periodic image, otherwise the forces calculated will be spurious. The size of the box defined here is su $\square$ cient for just about any cuto $\square$ scheme commonly used in simulations. Our system consists of, 596 water and 1 alkane molecule, 354 ethanol and 1 alkane molecule a separate system. After defining a system in a simulation box, energy minimization is carried out for each values of $\lambda$ from 0 to 1 , for $21 \mathrm{di} \square$ erent values to avoid unphysical van der Waals contact caused by the atoms that are too close [36]. Energy minimization brings the system to equilibrium configuration, removes all the kinetic energy from the system, reduces thermal noise in structure and brings the system to one of the local minimum. Steepest descent algorithm followed by L-BFGS (limited- memory- Broyden-Fletcher-Goldfarb-Shanno quasi- Newtonianmimimizer) [30, 31] algorithm has been used for energy minimization [36]. This combination (steepest descent and L-BFGS) yields a thoroughly-minimized structure suitable for starting equilibration and subsequent data collection. The energy (potential) of the system after energy minimization is shown in figure (2).

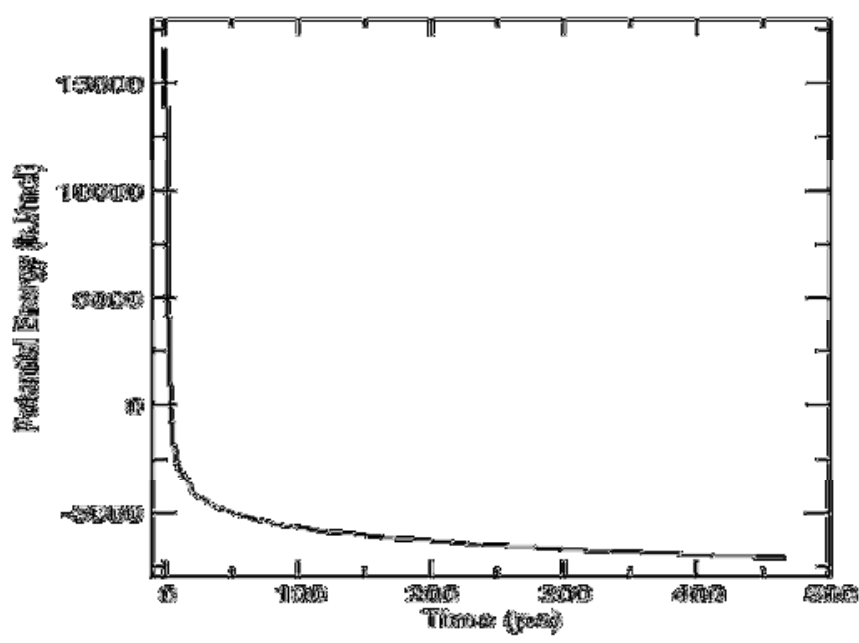

Fig. 2: Plot of potential energy as a function of time after energy minimization for methane-methanol system at $\lambda=0$ 
After energy minimization, NVT equilibration of $5 \times 10^{5}$ steps for $1 \mathrm{~ns}$ and isobaric-isothermal (NPT) equilibration of $2.5 \times 10^{6}$ of $5 \mathrm{~ns}$ was carried out at different temperature, from $275 \mathrm{~K}$ to $375 \mathrm{~K}$ and a pressure of $105 \mathrm{Nm}^{-2}$ by using velocity-rescaling thermostat [32] and Berendsen barostat [33] at a coupling time $\tau_{\mathrm{t}}=1.0 \mathrm{ps}$ and $\tau_{\mathrm{p}}=0.5 \mathrm{ps}$ respectively. Integration of the equations of motion were performed using an accurate leap-frog stochastic dynamics (SD) algorithm [34], and all bonds were constrained using LINC algorithm [35]. During equilibration, the long range Coulomb interac- tion is handled via the PME (Particle Mesh Ewald) algorithm [39, 40] with fourier spacing 0.12 with a real space cuto $\square$ of $1.2 \mathrm{~nm}$ and a PME order of 6 . We monitored the temperature, pressure, density, and energy of each studied system to bring it in thermodynamic equilibrium. After equilibration run we performed the production run to calculate the equilibrium properties of the system, that is free energy of solvation for each values of $\lambda$ by fixing the number of particles, volume and temperature i.e. NVT ensemble. We use velocity-rescale thermostat for this case. We don't couple the system to a fixed pressure and use the structure obtained after equilibration run by which we fix the volume of the system. The production run was carried out for $1 \mathrm{~ns}$ with the time step of $2 \mathrm{fs}$.

\section{Results and Discussion}

Using the computational details described above, free energy of solvation calculations were carried out in a cubic box in infinite dilution for two separate systems: (i) 596 TIP3P water molecules and 1 OPLS-AA alkane (methane, ethane, propane and n-butane) molecule (ii) 354 OPLS-AA methanol and 1 OPLS-AA alkane (methane, ethane, propane and n-butane) molecule. The free energy of solvation of alkanes in di $\square$ erent solvent environments, water and methanol were estimated by Eq.(14). The extent to which Hamiltonian of the system has been perturbed is measured by the free energy change of transforming a system from state $\mathrm{A}(\lambda=0)$ to state $\mathrm{B}(\lambda=1), \Delta \mathrm{A}$, as a function of a coupling parameter, $\lambda$. For decoupling van der Waals interactions, we used an equidistant $\lambda$ spacing of $21 \mathrm{di} \square$ erent $\lambda$ 's from 0 to 1 . Thus, the free energy change from $\lambda=0$ to $\lambda=1$ is simply the sum of the free energy changes of each pair of neighboring $\lambda$ simulations. The free energy changes of each pair of neighboring $\lambda$ and the cumulative free energy change which is negative of free energy of solvation of butane in water is shown in figure (3).

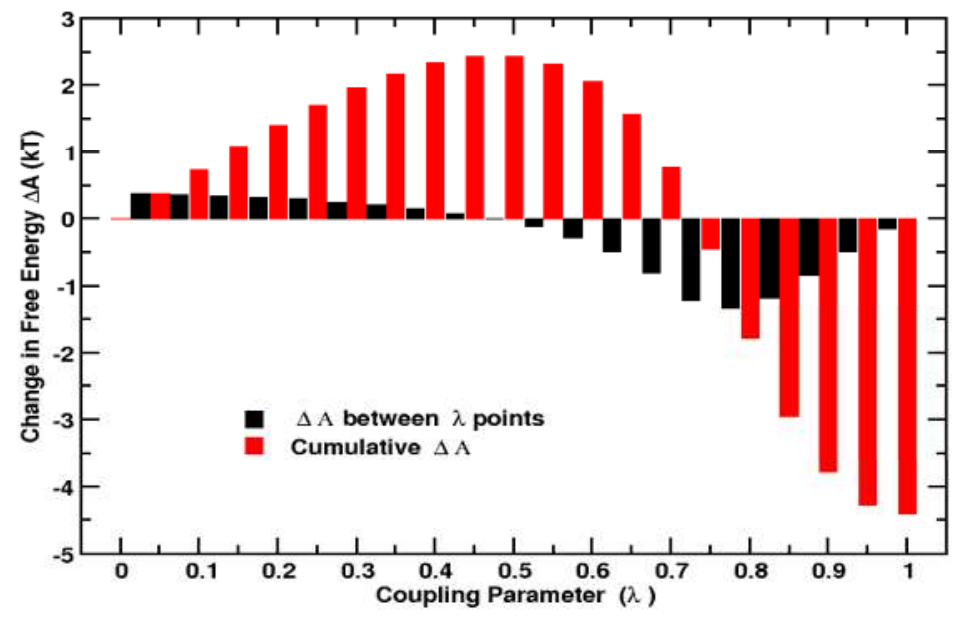

Fig. 3: Difference in free energy ( $\Delta \mathrm{A})$ and cumulative free energy di $\square$ erence ( $\Delta \mathrm{A})$ for di $\square$ erent $\lambda$ points for simulation of butane in water at $\mathrm{T}=300 \mathrm{~K}$. 
The calculated values of solvation free energy of alkane (methane, ethane, propane, n-butane) in water and methanol along with the references (if available) at different temperatures are presented in table (III). There is good agreement between experimental values at $298 \mathrm{~K}$ and calculated values at $300 \mathrm{~K}$ of the solvation free energy of alkanes in water within $15 \%$ error, but at higher temperatures there is no available experimental results. And there is no experimental available result for solvation free energy of alkanes in methanol.

Table III: Calculated and available experimental solvation free energies $\left(\mathrm{kJmol}^{-1}\right)$ at different temperature of light alkanes in water and methanol.

\begin{tabular}{|c|c|c|c|c|c|c|}
\hline \multirow{2}{*}{ Molecule } & \multirow[b]{2}{*}{$\mathrm{T}(\mathrm{K})$} & \multicolumn{2}{|l|}{ Water } & \multicolumn{3}{|l|}{ Methanol } \\
\hline & & Calculated & $\begin{array}{l}\text { Expt.[41] } \\
(298.15 \mathrm{~K})\end{array}$ & Calculted & & Ref. \\
\hline \multirow{5}{*}{ Methane } & 275 & $8.33 \pm 0.05$ & -- & $2.94 \pm 0.02$ & -- & \\
\hline & 300 & $9.08 \pm 0.12$ & 8.08 & $3.05 \pm 0.10$ & -- & \\
\hline & 325 & $10.01 \pm 0.14$ & -- & $3.36 \pm 0.01$ & -- & \\
\hline & 350 & $10.32 \pm 0.09$ & -- & $3.58 \pm 0.03$ & -- & \\
\hline & 375 & $10.63 \pm 0.07$ & -- & $3.79 \pm 0.05$ & -- & \\
\hline \multirow{5}{*}{ Ethane } & 275 & $8.22 \pm 0.14$ & -- & $0.20 \pm 0.15$ & -- & \\
\hline & 300 & $9.02 \pm 0.19$ & 7.41 & $0.70 \pm 0.12$ & -- & \\
\hline & 325 & $11.12 \pm 0.07$ & -- & $0.90 \pm 0.10$ & -- & \\
\hline & 350 & $11.20 \pm 0.10$ & -- & $0.99 \pm 0.10$ & -- & \\
\hline & 375 & $11.52 \pm 0.10$ & -- & $1.01 \pm 0.07$ & -- & \\
\hline \multirow{5}{*}{ Propane } & 275 & $8.77 \pm 0.14$ & -- & $-2.73 \pm 0.21$ & -- & \\
\hline & 300 & $9.61 \pm 0.21$ & 8.28 & $-1.28 \pm 0.30$ & -- & \\
\hline & 325 & $11.27 \pm 0.08$ & -- & $-0.93 \pm 0.16$ & -- & \\
\hline & 350 & $11.80 \pm 0.06$ & -- & -- & -- & \\
\hline & 375 & $12.70 \pm 0.20$ & -- & -- & -- & \\
\hline \multirow{5}{*}{ n-Butane } & 275 & $9.10 \pm 0.13$ & -- & $-4.92 \pm 0.19$ & -- & \\
\hline & 300 & $10.99 \pm 0.18$ & 9.03 & $-3.77 \pm 0.18$ & -- & \\
\hline & 325 & $11.82 \pm 0.11$ & -- & $-3.60 \pm 0.19$ & -- & \\
\hline & 350 & $12.95 \pm 0.20$ & -- & $-2.75 \pm 0.16$ & -- & \\
\hline & 375 & $13.93 \pm 0.11$ & -- & -- & -- & \\
\hline
\end{tabular}

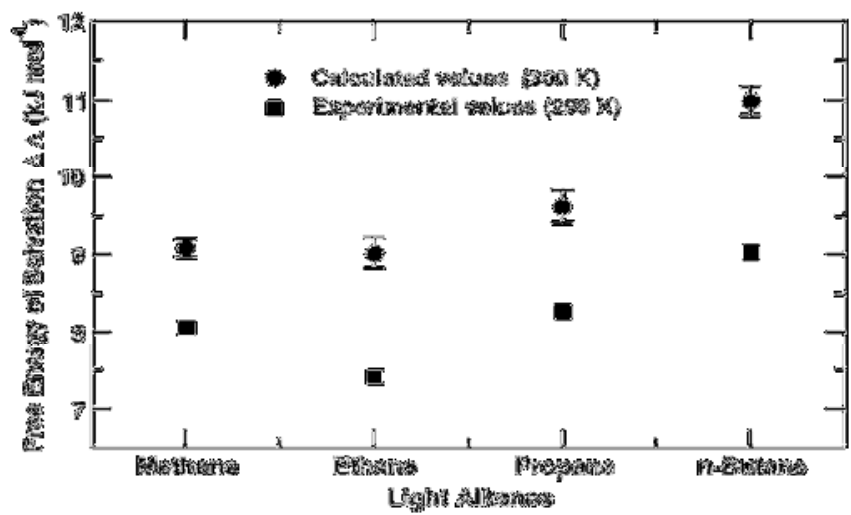

Fig. 4: Solvation free energy of alkanes in TIP3P water at $\mathrm{T}=300 \mathrm{~K}$. 


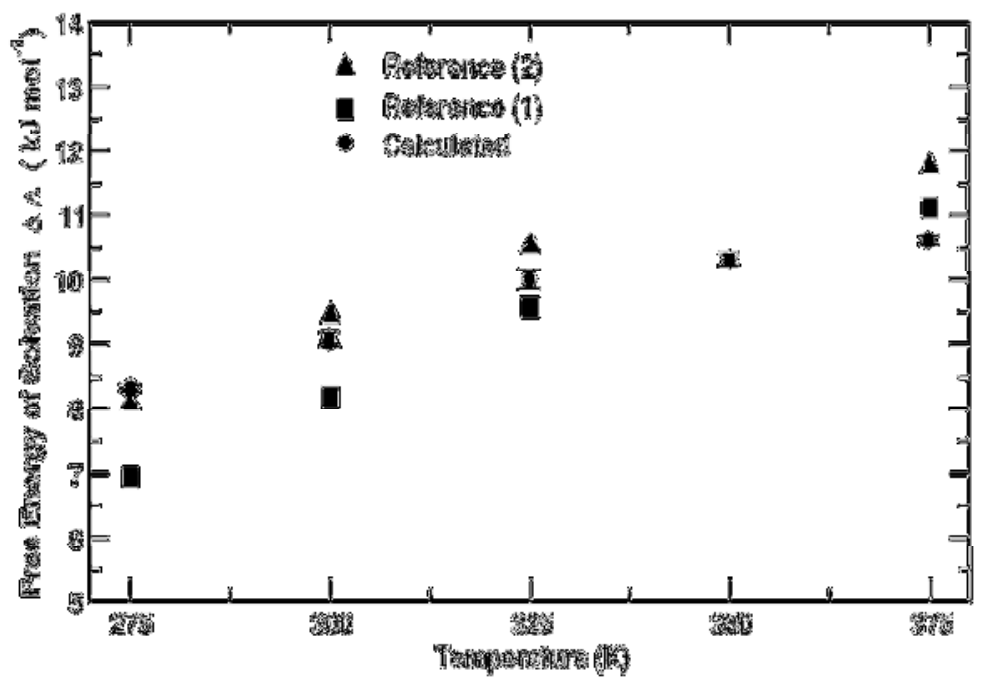

Fig. 5: Comparision of calculated and literature values (Reference (1) [42, 43], Reference (2) [44] of solvation free energy of methane in water at different temperature.

The comparison between the calculated values with error bars of solvation free energy of alkane in water at $300 \mathrm{~K}$ and the corresponding experimental values at $298 \mathrm{~K}$ is shown in figure (4). Similarly, the comparison of calculated and literature values of free energy of solvation of methane in water at di $\square$ erent temperature in shown in figure (5) and tabulated in table (IV). The free energy of solvation of alkanes (methane, ethane, propane and n-butane) in methanol as a fuction of temperature is plotted in figure (6).

Table IV: Calculated and reference (experimental and literature) values of solvation free energies $(\mathrm{kJ} / \mathrm{mol})$ at different temperature of methane in water.

\begin{tabular}{|l|l|l|l|l|}
\hline Molecule & $\mathrm{T}(\mathrm{K})$ & Calculated & Ref.(1)[42, 43] & Ref.(2) [44] \\
\hline & 275 & $8.33 \pm 0.05$ & 6.95 & 8.09 \\
& 300 & $9.08 \pm 0.12$ & 8.21 & 9.45 \\
Methane & 325 & $10.01 \pm 0.14$ & 9.58 & 10.54 \\
& 350 & $10.32 \pm 0.09$ & -- & -- \\
& 375 & $10.63 \pm 0.07$ & 11.13 & 11.78 \\
\hline
\end{tabular}

The solvation process is considered to consist of two steps, (i) the formation of a repulsive cavity of appropriate size, and (ii) the introduction of the soa lute into this cavity. The positive values of calculated free energies of solvation $(\Delta \mathrm{A})$ in TIP3P water for all of the alkanes (methane, ethane, propane and $\mathrm{n}$ butane) indicate their low solubilities in water that means alkanes are hydrophobic in nature. The simulations also show, in accordance with experiment, that $\Delta \mathrm{A}$ decreases from methane to ethane, but then increases with increasing carbon number for longer up to butane at $300 \mathrm{~K}$. This shows that the methyl group of alkane molecules have a preferential tendency to be dissolved in the vicinity of water molecules and that this tendency decreases with chain length. 


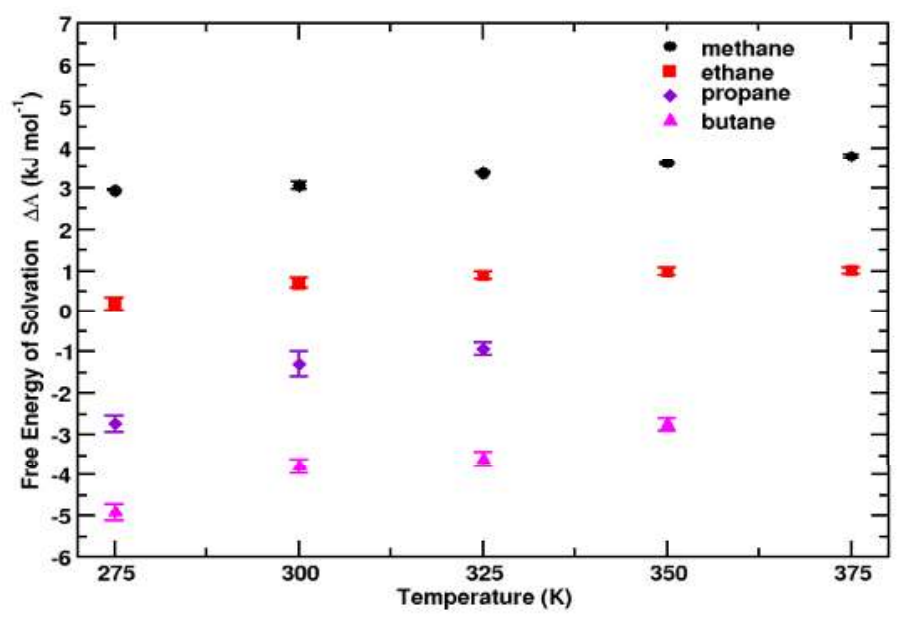

Fig. 6: Solvation free energy of alkane in methanol at different temperature from $\mathrm{T}=275 \mathrm{~K}$ to $\mathrm{T}=$ $375 \mathrm{~K}$.

The increase in free energy of solvation with increase in temperature describes that the formation of repulsive cavity in water is perturbed by the thermal agitation of the water molecules. That means when temperature is incresed we dont have new interactions that are strong enough to introduce some important change in enthalpy and change in Helmoltz free energy A is mostly connected with entropy or reordering of hydrogen bonds. By placing alkane in water we are perturbing the hydrogen bond network so that water molecules need to reorganize themselves around the solvent in a particular way that makes possible for average number of bonds for one molecule to remain constant. Since hydrogen bonds are directional this leads to a smaller configurational space for water molecules and change in entropy will be negative $45,46]$. Again, we have calculated free energy of solvation of alkanes in methanol at di $\square$ erent temperature. From table (III) and figure (6), free energy of solvation $\Delta \mathrm{A}$ in methanol becomes more negative as the alkane chain increases. The positive values of solvation free energy of methane and ethane shows that they are insoluble in methanol but the negative values of it for propane and butane indicates they are soluble in the methanol. Methanol is amphiphilic organic substance. There is a competition between hybrophobic group (methyl- $\mathrm{CH}_{3}$ ) and a hydrophilic group (hydroxyl-OH). Amphiphilic nature makes methanol interesting solvent because alkanes should show greater solubility in it than in water. For methane and ethane the hydrophobic groups dominates over the hydrophilic group, on the other hand for propane and butane the reverse situation occurs.

\section{Conclusions and Concluding Remarks}

In this work, we have computed free energy of solvation (Helmholtz free energy A ) of alkane (methane, ethane, propane, n-butane) molecules in different solvent environments - water as a polar and methanol as an amphiphilic solvent, for various temperatures $275 \mathrm{~K}, 300 \mathrm{~K}, 325 \mathrm{~K}, 350 \mathrm{~K}, 375 \mathrm{~K}$, using molecular dynamics simulation technique. The Transferable Intermolecular Potential with 3-Points (TIP3P) model of water and the Optimized Potential for Liquid Simulations- All Atom (OPLS-AA) model of alkane and methanol were used. Here alkane (methane, ethane, propane and n-butane) acts as a solute and water and methanol act as a polar and an amphiphilic solvent respectively. The free energy of solvation or hydration 
of alkane in water is positive, and this values increases with increase in change length of alkanes. The calculated values of the free energy are in agreement with the available literature values. The free energy of solvation of alkanes in methanol shows different trends, it is negative for propane and butane but positive for methane and ethane. This shows that methane and ethane are insoluble whereas propane and butane are soluble in methanol.

This study reports the first complete description of the solution thermodynamics calculating solvation free energy of alkanes in water and methanol by computer simulations, using Bennet Acceptance Ratio (BAR) method. This study could be the basis for understanding the biomolecular interactions and calculation of free energy of binding for a small molecule to some larger receptor biomolecule (usually a protein). In the near future, we also plan to study the solvation/hydration of a larger series of solutes and calculation free energy of binding between a ligand and a receptor in di $\square$ erent aqueous environment.

\section{Acknowledgements}

S. Pokharel acknowledges the receipt of the grant from the Abdus Salam International Centre for Theoretical Physics, Trieste, Italy through the office of external activities (OEA) for the PhD studies. N.P. Adhikari acknowledges the UGC Award no. CRG-73/74-S\&T-01. S.P. Khanal acknowledges the partical financial support from Nepal Academy of Science and Technology (NAST), Nepal. We further acknowledge the computing facilities by ICQ-13.

\section{References}

[1] T. P. Straatsma, H. J. C. Berendsen, and J. P. M. Postma, Free energy of hydrophobic hydration: A molecular dynamics study of noble gases in water, J. Chem. Phys. 85 (1986) 6720.

[2] C. N. Pace, B. A. Shirley, M. McNutt, and K. Gajiwala, Forces contributing to the conformational stability of proteins, FASEB Journal. 10 (1996) 7583.

[3] J. W. Steed, and J. L. Atwood, Supramolecular Chemistry, 2nd ed. Wiley, (2013).

[4] Alireza Mashaghi et al., Hydration strongly affects the molecular and electronic structure of membrane phospholipids, J. Chem. Phys. 136 (2012) 114709.

[5] M Bonn, H.J. Bakker, Y. Tong, E. H. Backus, No ice-like water at aqueous biological interfaces, Biointerphases. 7 (2012) 20.

[6] D. Frenkel, B. Smit, Understanding Molecular Simulation From Algorithms to Applications, Academic Press, U. S. A, (2002).

[7] M. P. Allen, D. J. Tildesley, Computer Simulation of Liquids, Oxford University Press, U. S. A (1989).

[8] H. J. C. Berendsen, Simulating the Physical World , Cambridge University Press, (2007).

[9] A. Satoh, Introduction to Practice of Molecular Simulation, Elsevier, (2011).

[10] D. C. Rapport, The Art of Molecular Dynamics Simulation, Cambridge University Press, Second Edition, (2004)

[11] O. M. Becker, A. D. MacKerell, Jr. B. Roux, M. Watanabe, Computational Biochemistry and Biophysics, Marcel Dekker, Inc. (2001).

[12] R. T. Morrison, R. N. Boyd, Organic Chemistry, Pearson, 7 th Edition, (2011).

[13] J. McMurray, Organic Chemistry, Seventh Edition, Physical Sciences: David Harris, (2008).

[14] W. H. Brown and T. Poon, Introduction to Organic Chemistry, 5 th Edition, John Wiley and Sons, Inc. (2014)

[15] J. D. Roberts, M. C. Caserio, Basic Principles of Organic Chemistry, W.A. Benjamin Inc, 2nd Edition, (1977)

[16] T. A. Weber, Simulation of n-butane using a skeletal alkane model, J. Chem. Phys. 69 (1978) 2347.

[17] M. R. Shirts et al., Extremely precise free energy calculations of amino acid side chain analogs: Comparison of common molecular mechanics force fields for proteins, J. Chem. Phys. 119 (2003) 5740. 
[18] M. R. Shirts and V. S. Pande, Solvation free energies of amino acid side chain analogs for common molecular mechanics water models, .J. Chem. Phys. 122, 134508 (2005).

[19] S. K. Murphy, and Park, J. W. Park and Cruz, F. A. Cruz and V. M. Dong, Rh-catalyzed C--C bond cleavage by transfer hydroformylation, Science, 347 (2015) 6217.

[20] P. L. Privalov and S. J. Gill, Stability of protein structure and hydrophobic interaction, Adv. Protein Chem. 39 (1988) 191.

[21] J. Kyte, Structure in Protein Chemistry, Second Edition, Taylor \& Francis Group (2007).

[22] R. K. Pathria and P. D. Beale, Statistical Mechanics, Academic Press, 3 rd Edition, (2011).

[23] K. Huang, Statistical Mechanics, 2nd Edition, John Wiley (1987).

[24] J. G. Kirkwood, Statistical mechanics of fluid mixtures, J. Chem. Phys. 3 (1935) 300.

[25] M. Fasnacht, R. H. Swendsen, and J. M. Rosenberg, Adaptive integration method for Monte Carlo simulations, Phys. Rev. E, 69 (2004) 056704

[26] R. W. Zwanzig, High-temperature equation of state by a perturbation method, I. Nonpolar gases. J. Chem. Phys. 22 (1954) 1420.

[27] C. H. Bennett, Efficient estimation of free energy differences from Monte Carlo data, J. Comput. Phys. 22 (1976) 245

[28] W. L. Jorgensen, J. Chandrasekhar, J. D. Madura, R.W. Impey, M. L. Klein, Comparison of simple potential functions for simulating liquid water, J. Chem. Phys. 79 (1983) 926935

[29] G. A. Kaminski, R.A. Friesner, J.Tirado-Rives and W.L. Jorgensen, Evaluation and reparametrization of the OPLS-AA force field for proteins via comparison with accurate quantum chemical calculations on peptides, J. Phys. Chem. B 105 (2001) 6474.

[30] R. H. Byrd, P. Lu, J. Nocedal, C. Zhu, A limited memory algorithm for bound constrained optimization, SIAM Journal on Scientific Computing 16 (1995) 1190.

[31] C. Zhu, R. H. Byrd, P. Lu, J. Nocedal, Algorithm 778: L-BFGS-B: Fortran subroutines for large-scale bound-constrained optimization, ACM Trans, Math. Softw. 23 (1997) 550

[32] G. Bussi, D. Donadio, M. Parrinello, Canonical sampling through velocity rescaling, J. Chem. Phys. 126,(2007) 014101.

[33] H. J. C. Berendsen, J. P. M. Postma, A. DiNola, J. R. Haak, Molecular dynamics with coupling to an external bath, J. Chem. Phys. 81 (1984) 36843690

[34] W. F. van Gunsteren, H. J. C. Berendsen, A leap-frog algorithm for stochastic dynamics, Mol. Sim. 1 (1988) 173.

[35] B. Hess, H. Bekker, H. J. C. Berendsen, J. G. E. M. Fraaije, LINCS: a linear constraint solver for molecular simulations. J. Comp. Chem. 18, 1463-1472, (1997).

[36] D. van der Spoel, E. Lindahl, B. Hess, A. R. van Buuren, E. Apol, P. J. Meulenhoff, D. P. Tieleman, A. L. T. M. Sijbers, K. A. Feenstra, R. van Drunen and H. J. C. Berendsen, Gromacs User Manual version 5.1.1, (2016)

[37] D. van Der Spoel, E. Lindahl, B. Hess, G. Groenhof, A. E. Mark, H. J. C. Berendsen, GROMACS: fast, flexible, and free, J. Comp. Chem. 26 (2005) 1701.

[38] B. Hess, C. Kutzner, D. van der Spoel, E. Lindahl, GROMACS 4: algorithms for highly efficient, loadbalanced, and scalable molecular simulation, J. Chem. Theory Comp. 4 (2008) 435.

[39] T. Darden, D. York, L. Pedersen, Particle mesh Ewald: An N $\square \log (\mathrm{N})$ method for Ewald sums in large systems, J. Chem. Phys. 98 (1993) 10089.

[40] U. Essmann et al., A smooth particle mesh Ewald method, J. Chem. Phys. 103 (1995) 8577.

[41] A. Ben-Naim, and Y. Marcus, Solvation thermodynamics of nonionic solutes, J. Chem. Phys. Physics 81 (1984) 2016.

[42] D. Paschek, Temperature dependence of the hydrophobic hydration and interaction of simple solutes: An examination of five popular water models, J. Chem. Phys. 120 (2004) 6674. 
[43] R. F. Prini and R. Crovetto, J. Phys. Chem. Ref. Data, 18 (1998) 1231.

[44] H. Docherty, A. Galindo, C. Vega and E. Sanz, A potential model for methane in water describing correctly the solubility of the gas and the properties of the methane hydrate, J. Chem. Phys. 125 (2006) 074510.

[45] Jianzhong $\mathrm{Wu}$ and John M. Prausnitz, Pairwise-additive hydrophobic effect for alkanes in water, PNAS 105 (2008) 9515.

[46] Michael H. Abraham and Enrico Matteoli, The temperature variation of the hydrophobic effect, J. Chem. Soc., Faraday Trans. 1, 84 (1988) 1985-2000.

[47] S. Pokharel, N. Pantha and N. P. Adhikari, Diffusion coefficients of nitric oxide in water: A molecular dynamics study, International Journal of Modern Physics B 30 (2016) 1650205 